\section{Motherhood and apple pie}

\author{
Phil Wiffen
}

Last month saw the much publicised European Association of Hospital Pharmacists (EAHP) summit take place in Brussels. Over 100 delegates representing 34 European countries gathered to debate and discuss a series of statements about hospital pharmacy. The summit set out to develop a set of statements for hospital pharmacy that are relevant to Europe. These built on the International Pharmaceutical Federation (FIP) global hospital pharmacy statement that was published in $2008 .^{1}$ A full report of the meeting with papers on the underpinning methodology and the full statements will be published in a future issue of EJHP.

This was a well organised and managed event with the majority of the day-and-a-half of meetings being used to discuss and refine the proposed statements. Every delegate had the opportunity to discuss each statement in a café style meeting where delegates moved around a number of stations. The value of the discussions was enhanced by the attendance of both patient groups and non-pharmacy professions.

The meeting was able to move forward smoothly because of a large amount of preparation during the previous 18 months to develop the draft statements using a Delphi process.

One of the textbooks ${ }^{2}$ on Delphi defines the process as 'a method for structuring a group communication process so that the process is effective in allowing a group of individuals, as a whole, to deal with a complex problem.' In practice, it is a communication method whereby questionnaires are used to develop responses to particular issues. These are then collated and replayed to the original contributors as a means of obtaining consensus.

Correspondence to Professor Phil Wiffen, Pain Research Unit, Churchill Hospital, Oxford OX3 7LE, UK; phil.wiffen@ndcn.ox.ac.uk
Dr Roberto Frontini stated that: "Through the new European Statements of Hospital Pharmacy, patients, hospital pharmacists and our sister healthcare professionals have set out a clear vision for what hospital pharmacy should be achieving in every European country."

The end result was agreement on 44 statements in six sections as follows:

Section 1: Introductory Statements and

Governance-seven statements

Section 2: Selection, Procurement and

Distribution-seven statements

Section 3: Production and Compounding — six statements

Section 4: Clinical Pharmacy Services —eight statements

Section 5: Patient Safety and Quality Assurance-11 statements

Section 6: Education and Researchfive statements

The agreed statements are currently available on the EAHP website. ${ }^{3}$

These statements need to be examined by every senior hospital pharmacist in Europe for several reasons. First, for many they will bring reassurance that the services they are providing or aspiring to are on the right lines. Second, they are useful in determining the direction of travel for hospital pharmacy particularly where current services fall below the standard of the statements. Third, the statements may well develop some political weight that can be used to persuade hospital administrators to provide support and release funds to improve services locally.

The phrase 'Motherhood and apple pie' is almost certainly from the USA some 75 years ago. It implies values that few would argue with. So, are the consensus statements just 'Motherhood and apple pie'? For some they will be though I do not believe that they represent a lowest common denominator for hospital pharmacy across Europe. There are significant challenges within these statements in each of the sections. Even the most developed hospital pharmacy services in Europe will need to adapt. For those less well developed, there are some major challenges that will require a strategy to develop in line with these aspirations. While it is probably unfair to select just one or two, one that I am excited about is statement 6.4 that states hospital pharmacists should actively engage in and publish research, particularly on hospital pharmacy practice. If accepted and implemented, this bodes well for the future of hospital pharmacy and also for this journal.

The challenge now is to see these statements discussed and implemented in hospital pharmacies across Europe. Guidelines are relatively easy to develop and notoriously difficult to implement.

Dr Roberto Frontini continued in his quotation to say: "EAHP will roll out a series of tools and initiatives to support the achievement of the statements, but a major onus now falls on health systems to prepare the way for improvement as well. The positive support from patient organisations and other healthcare professionals assures us that the statements are a shared aspiration and provide a route towards continuously improving patient care within hospitals in every European country."

EJHP supports the developments and will publish relevant wisdom and discussion as we move forward.

Competing interests None.

Provenance and peer review Commissioned; internally peer reviewed.

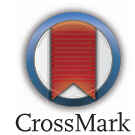

To cite Wiffen P. Eur J Hosp Pharm 2014;21:193.

Accepted 11 June 2014

Eur J Hosp Pharm 2014;21:193.

doi:10.1136/ejhpharm-2014-000498

\section{REFERENCES}

1 https://www.fip.org/baselstatements

2 Linstone HA, Murray T. eds. The Delphi method: techniques and applications. Addison-Wesley Pub Co. Advanced Book Program, 1975.

3 http://www.eahp.eu/events/european-summit/summitdocuments 